\title{
Alvares de Azevedo na Academia
}

Conferencia realisada no Salão Nobre da Faculdade de Direito de S. Paulo, em commemoração ao primeiro centenario do nascimento do poeta, pelo professor DR. SPENCER VAMPRÉ, representante da Congregação dos Professores.

Na rua da Cruz Preta, que depois se chamou rua do Principe, e hoje Quintino Bocayuva, no cruzamento com a rua da Freira, hoje Senador Feijó, erguia-se, desde antes de 1827, anno da fundação dos Cursos Juridicos, uma grande cruz tosca, a cujo sopé vinham á noite os devotos rezar orações silenciosas, e accender velas votivas. Amparava-se a cruz contra a parede de uma casa senhorial, que ainda hoje perdura, por muito tempo depois pertencente ao famoso advogado João Mendes de Almeida, pae do nosso João Mendes Junior, e ainda agora na propriedade de herdeiros.

Morava então nessa casa o dr. Silveira da Motta, $\left(^{\star}\right)$

(*) Segundo outra versão, que nos foi transmittida por D. Sinhá Prad'o Guimarães, esposa do illustre advogado dr. Alvaro Macedo Guimarães, a casa em que nasceu Alvares de Azevedo, foi uma casa baixa, ainda hoje existente, no Largo do Ouvidor, em frente á estatua de José Bonifacio, e á "Casa dos Presentes" de Otto Schloembach. 
que tinha uma filha formosa, e de cuja formosura se encantou mais de um estudante.

Della se enamorou Ignacio Manoel Alvares de Azevedo, e naquelles tempos romanticos galgou uma noite a cruz, para, - novo Romeu, - conversar mais de perto com a sua Julieta. Souberam-no os estudantes, porventura collegas do namorado, e, ajustados em conciliabulo, foram, trinta ou quarenta, a deshoras, roubar a Cruz veneravel, e atiraram-na no Anhangabahú, ainda então canalisado, no Largo do Bexiga, hoje Largo do Riachuelo.

Recolheu-a, na manhã seguinte, Manoel José da Ponte, negociante no local, e com outros devotos lhe erigiu uma capella, que largo tempo confortou almas afflictas - a velha e tradicional Santa Cruz do Piques.

Do consorcio, realisado pouco depois, entre Ignacio Manoel e D. Maria Carlota (assim se chamava a linda senhora), nasceu aos 12 de Setembro de 1831, precisamente ha um seculo, o nosso Manoel Antonio Alvares de Azevedo.

Não admira que, provindo de amores tão romanticamente delineados, viesse o poeta, vinte annos depois, constituir-se uma das figuras de maior relevo na corrente literaria do romantismo.

Mas, deixemos a outrem julgar-lhe os meritos. Queremos retraçar, apenas, em pinceladas rapidas, o que mais importa á festividade de hoje - a saber, como viveu, estudante, o celebrado poeta, cujo centenario aqui nos congrega.

Eil-o, em 1848, matriculado no primeiro anno juridico.

Exercia então, interinamente, a directoria, Amaral Gurgel; era secretario Brotero, e bibliothecario Agostinho Marques Perdigão Malheiro, que não sonhava ainda consagrarse jurisconsulto. A Congregação, reduzida ainda, por ser pequeno o numero de cadeiras, não alcançara aquelle brilho e aquella fama, que dentro em pouco a viriam aureolar: no primeiro anno, Avellar Brotero, que seguia a turma até o segundo, alternando com Amaral Gurgel, e explicando o direito natural, publico, das gentes e diplomacia; no segundo anno, ainda Avellar Brotero ou Amaral Gurgel, acompa- 
nhando a turma, e continuando as materias do primeiro. Explicavam pelo compendio, adoptando-se os Elementos de Direito Natural de Perreau, o tratado de igual nome de Vicente Ferrer Netto de Paiva, o Tratado do Direito das Gentes, de Vattel, e o Manual Diplomatico do Barão de Martens. A Constituição Imperial era lida e analysada no proprio texto.

No segundo anno, leccionava o Padre Anacleto Coutinho, parafraseando as "Instituições de Direito Ecclesiastico" de Gmeiner, na parte em que tratavam do direito publico, supprindo-as com adaptações de leis e instituições brasileiras.

No terceiro anno, em direito criminal, Manoel Dias de Toledo, que analysava o Codigo Criminal Brasileiro, de 1831, comparando-o com as theorias dos melhores criminalistas; e, em direito civil, alternadamente, Pires da Motta ou Veiga Cabral, pelas Instituições de Direito Civil Portuguez, de Mello Freire, a que se accrescentavam as modificações das leis patrias.

No quarto anno, em direito civil, ainda um destes ultimos, acompanhando a turma, e em direito commercial, Falcão, pae, o rispido e irritavel Falcão, que explanava o Codigo do Commercio Francez, e commentava o Systema Universal, ou Principios do Direito Maritimo da Europa, por Azuni.

No quinto anno, em economia politica, Carneiro de Campos, servindo de texto ás explicações o Cathecismo de Jean Baptista Say, e, em Theoria e Pratica do Processo, Silveira da Motta, aproveitando-se das doutrinas de Mello Freire na parte processual, e de notas de preparação para um livro futuro, que não chegou a publicar.

Eram substitutos: - Crispiniano, Ramalho, Couto Ferraz e Carrão.

Eis os lentes, e o seu ensino. Não poderia ser notavel, escassos que eram então os monumentos legislativos. Basta considerar que a Lei Hypothecaria veio apenas em 1864; 
o Codigo Commercial e o Regulamento n. 737, em 1850, bem como a Lei de Terras.

Pode-se bem imaginar o atrazo dos methodos e das doutrinas, atrazo, bem se entende, em relação a nós, pois constituiam o que melhor produzia então a sciencia franceza, de cujo leite, desde ahi, permanentemente nos alimentámos.

Foi nesta Academia, cujo aspecto material é ainda o mesmo do seu tempo, mas cujos progressos moraes se assignalaram, desde então, notavelmente, que Alvares de Azevdo abriu os olhos aos primeiros conceitos da sciencia de Ulpiano, e abriu o coração aos primeiros echos da musa de Byron.

Acolheu-o, na colmeia sussurante, uma revoarda de abelhas do Hymeto. Não contava a Academia ao todo sessenta estudantes, mas dentre elles, muitos recorda a posterioridade, nas letras juridicas, ou nas profanas: - Agostinho Marques Perdigão Malheiro, que referimos ha pouco; Carlos Arthur Busch Varella, advogado eminente; Olegario Herculano de Aquino e Castro, que falleceu Ministro do Supremo Tribunal; João Cardoso de Menezes e Souza, mais tarde Barão de Paranapiacaba; Paulo Antonio do Valle, o collecionador do Parnaso Academico. Eram estes os principaes quinto-annistas, quando, em 1848, se alistou Alvares de Azevedo nas fileiras academicas.

Entre os quarto-annistas referiremos Antonio Augusto da Fonseca, distrahidissimo, que se tornou advogado de grande renome em Rio Claro, Bernardo Avelino Gavião Peixoto e Antonio da Costa Pinto, mais tarde politicos de grande prestigio. Cursavam o terceiro anno:- Justino Gonçalves de Andrade, mais tarde lente afamado; Joaquim Felicio dos Santos, destinado a precursor do Codigo Civil; José Martiniano de Alencar, que não sonhava ainda com Iracema, e Bernardo Joaquim de Silva Guimarães, que já se estreara como poeta e como poeta de bestialogicos, mas nem siquer ainda imaginara a Escrava Isaura.

Laurindo de Brito e Aureliano José Lessa figuravam 
entre os estudantes do segundo anno. Taes os principaes academicos, que o viram chegar a este velho Convento de S. Francisco.

Por sua vez, a turma de Alvares de Azevedo recebeu, no anno seguinte, de 1849, José Bonifacio de Andrada e Silva, que encheria mais tarde o Parlamento, a Academia e o Parnaso, com os accentos de sua oratoria, e com a delicadeza de seus ritmos; André Augusto de Padua Fleury, que haveria de ser director desta Faculdade; Leonel Martiniano de Alencar, irmão de José de Alencar, que esqueceu as letras pela diplomacia; Pedro Taques de Almeida Alvim, mais tarde jornalista e politico, prematuramente arrebatado pela morte; Francisco Aurelio de Souza Carvalho, o Chico Aurelio, por muitos annos professor de geometria nas aulas menores, e pae do actual professor dr. Theofilo Benedicto de Souza Carvalho.

No anno seguinte, de 1850, engrossam as fileiras: Felix Xavier da Cunha, José Maria Corrêa de Sá e Benevides, mais tarde lente, Manoel Francisco Corrêa, Sebastião Pereira, que depois foi Juiz nesta Capital; Thomaz Alves Junior, o commentador do Codigo Criminal.

Em 1851, vieram assentar-se nestes bancos:- Americo Brasiliense de Almeida Mello, Antonio Carlos Ribeiro de Andrada Machado e Silva, Clemente Falcão de Souza Filho, e Vicente Mamede de Freitas, todos mais tarde lentes, a que devemos accrescentar Antonio Ferreira Vianna, Caetano José de Andrade Pinto, Manoel da Silva Mafra e Paulino José Soares de Souza.

Quintino Bocayuva, já jornalista, redigindo $O$ Acayaba, € depois A Hora, com Ferreira Vianna, não pertenceu á Academia, embora affectuosamente ligado a ella.

Em Março de 1852, quando Alvares de Azevedo se debatia nas ultimas convulsões, nova e luzida turma penetrava estes umbraes: - Manoel Antonio Duarte de Azevedo, que haveria de ser lente insigne, ligado ao poeta por laços de parentesco; Americo Pinheiro e Prado, Rodrigo Silva, 
Joaquim Lopes Chaves e Flavio Farnese da Paixão Junior, estavam entre elles.

Abria-se então á vida mental desta Faculdade fase nova e original, em que o talento dos estudantes prenunciava as glorias com que se ensoberbeceu depois.

Os nomes que se seguem - de Lafayette, Gaspar Martins, Affonso Celso, o velho, e outros, e outros, pertencem já quasi aos nossos tempos.

Vimos a Academia. Penetremos agora no quarto do estudante. Elle mesmo o descreve na poesia Idéas Intimas:

Enchi o meu salão de mil figuras:

Aqui vôa um cavallo no galope;

Um roxo dominó as costas volta

A um cavalleiro de allemães bigodes;

Um preto beberrão sobre uma pipa

Aos grossos beiços a garrafa aperta.

Ao longo das paredes se derramam

Extinctas inscripções de versos mortos,

$E$ mortos ao nascer! Alli, na alcova,

Em aguas negras se levanta a ilha

Romantica, sombria, á flor das ondas,

De um rio que se perde na floresta.

A mesa escura cambaleia ao peso

Do titaneo Digesto; $e$, ao lado delle,

Childe Harold entre-aberto... ou Lamartine

Mostra que o romantismo se descuida

$E$ que a poesia sobrenada sempre

Ao pesadelo classico do estudo.

Reina a desordem pela sala antiga,

Desce a têa de aranha, ás bambinelas,

A' estante pulvurenta. A rollpa, os livros

Sobre as poucas cadeiras se confundem.

Marca a folha do "Faust" um collarinho,

$E$ Alfredo de Musset encobre, ás vezes,

De Guerreiro ou Valasco um texto obscuro.

Como outrora do mundo os elementos

Pela treva jogando em cambalhotas,

Meu quarto, mundo em cáos, espera um "Fiat"! 
Fôra longa a descripção. Ha ainda outros quadros: Victor Hugo, em cuja "larga fronte, erguidos luzem os cabellos loiros, como corôa soberba"; Lamenais, "o bardo santo", "alma de santo na mundana argila", por quem "a Georges Sand morreu de amores". Junto ao leito, com as mãos unidas, olhos fitos no céo, cabellos soltos, uma sombra de mulher parece rezar e chorar. Em frente, em negro quadro, uma figura feminil que dorme. Parece que o poeta preferia este quadro aos demais:

"Oh! quantas vezes, ideal mimoso, Não encheste minh'alma de ventura, Quando louco, sedento, e arquejante, Meus tristes labios imprimi ardentes No poento vidro que te guarda o somnol"

Junto ao leito dormem os poetas predilectos - o Dante, a Biblia, Shakespeare e Byron; e, entre elles, o candieiro:

Oh! mea amigo, oh! velador nocturno,

Tu não me abandonaste nas vigilias, Quer eu perdesse a noite sobre os livros, Quer, sentado no leito, pensativo, Relesse as minhas cartas de namoro. Quero-te muito bem, oh! meu comparsa Nas doudas scenas do meu drama obscuro! E num dia de "spleen", vindo a pachorra, Hei de evocar-te, dum poema heroico, Na rima de Cámóes e de Ariosto, Como padrão ás lampadas futuras!

Mais adeante, os charutos, e um querido cachimbo allemão, que aquelas, semanas a fio, relegam á ingratidão do esquecimento. E, em tudo, tristeza e spleen:

Passeio os dias

Pelo meu corredor, sem companheiro, Sem ler, nem poetar . Vivo fumando;

Minha casa não tem menores nevoas

Que as deste céo de inverno. Solitario, 
Passo as noites aqui $e$ os dias longos...

Dei-me agora as charuto em corpo e alma:

Debalde alli de um canto um beijo implora,

Como a belleza que o Sultão despreza,

Meu cachimbo allemão abandonado!

Nẫo passeio a cavallo e não namoro.

Odeio o "lasquenet". Palavra de honra!

Si assim me continuam por dois mezes

Os diabos azues nos frouxos membros,

Dou na Praia Vermelha, ou no Parnaso.

De outra vez escreveu:

Vivi na solidão, odeio o mundo...

$E$ no orgulho embucei meu rosto pallido,

Como um astro nublado.

Mas, não se tomem ao pé da letra estes accessos de violento pessimismo. Elle proprio, mais adeante, sonha com a gloria, e a inspiração de subito lhe enche o verso, com accentos que fazem lembrar os que mais tarde desferiria Castro Alves:

Fôra bello talvez, em pé, de novo,

Como Byron, surgir, oll, na tormenta

o homem de Waterloo!

Com sua idéa illuminar um povo,

Como o trovão da nuvem que rebenta

$E$ o raio derramou.

Fôra bello, talvez, sentir no craneo

A alma de Goethe, e resumir na fibra

Milton, Homero e Dante,

Sonhar-se, num delirio momentaneo,

A alma da creação, e o som que vibra

A terra palpitante.

Sente-se que faltou ao poeta um amor de mulher que the enchesse a vida de lyrismo e poesia; amor unico a que todos aspiram, e que poucos tem - amor capaz de reflorir em cantos e em queixas, unindo e resplendendo ao triplice clarão da 
mocidade, da poesia e da morte; amor que se toca de infinito, e que é treva e clarão, pesadelo e sonho, ambição e martirio, delicia e veneno. 0 cantor, que, por ironia do destino, tomou para si este verso celebre

Foi poeta, sonhou e amou na vida,

não encontrou a suprema exaltação dos sentidos, que tem todos os aéstos, a orchestração fantastica de côres e de sons, que tem todas as vibrações e todas as ancias, e conturba a alma apaixonada, fazendo do amor uma doença.

$\mathrm{E}$ por isso cantava assim:

Eu vaguei pela vida sem conforto

Esperei o meu anjo, noite e dia

$E$ o ideal não veio.

Farto de vida, breve serei morto...

Nem poderei, ao menos, na agonia,

Descansar-lhe no seio...

Passei como Don Juan entre as donzellas,

Suspirei as canções mais doloridas,

$E$ ninguem me escutou.

Oh! nunca á virgem flôr das faces bellas

Sorvi o mel nas longas despedidas.

Meu Deus! ninguem me amou.

Mas, deixemos á critica literaria a contemplação destes lavores, ou o bosquejar dos laços que os unem á feição literaria do poeta.

Cabe-nos tarefa mais singela: - levantar uma ponta av véo do passado, e vislumbrar-lhe a vida de estudante, caminhando com elle um momento.

Não o imagineis, porém, sempre solitario e triste. A tristreza e a solidão, como duas aves de rapina, o salteiam na fase final, nas férias do segundo anno em deante, si é que se pode dizer final qualquer fase de uma brevissima vida literaria, que toda se extendeu por quatro annos, e onde principio e fim necessariamente se confundem. 
É então que o poeta costumava dizer

Eu deixo a vida, como deixa o tedio

Do deserto o poento caminheiro...

Vive só, fechado no quarto, longe de Aureliano Lessa e de Bernardo Guimarães, seus amigos queridos, com os quaes cogitara publicar uma collectanea de versos de todos tres, sob o titulo de Lyra dos Vinte Annos.

Antes disso, porém, ou nas intermitencias deste solitario viver, procurava alguns amigos, ou estes o iam buscar, e por noite escura e invernosa, ao redor da mesa, allumiados pelo baço clarão do candieiro, entre o fumo de charutos ou dos cachimbos, a que se entremeava, de quando em quando, o cognac de Johanisberg, "horror de labios femininos" e inspiração de tantos versos, Alvares de Azevedo passava horas a fio, em palestras literarias, em disputas escolasticas, em extravagantes fantasias, cortadas de espaço a espaço por uma anecdota, ou por um dicto picante.

Outras vezes, porventura mais raras, se reuniam os estudantes na "Sociedade Epicuréa", fundada em 1845, antes, portanto, de matricular-se Alvares de Azevedo na Academia.

Propunha-se a associação este objectivo extravagante - "realisar os sonhos de Byron".

Reunidos ora na Chacara dos Inglezes, ora em arrabalde da cidade, passavam dias inteiros, e, muita vez, noites e semanas, entre os prazeres do espirito e estudantadas exoticas. "Uma vez estiveram encerrados quinze dias, - narra o contemporaneo Paulo do Valle, -- em companhia de perdidas, commettendo, ao clarão de candieiros, (por isso que todas as janellas eram perfeitamente fechadas desde que entravamos até sahir), toda a sorte de desvarios que se podem conceber".

E a taes excessos se entregaram, que alguns contrahiram molestias de que depois vieram a morrer.

Advinha-se que a "Noite da Taverna" se inspirou nes- 
tas scenas, onde a embriaguez dos convivas se casava ás mais altas discussões filosoficas.

Mas, não só na Sociedade Epicuréa, que parece ter tido feição de associação secreta, para alguns iniciados. Em 3 de Maio de 1850, figura Alvares de Azevedo entre os fundadores do "Ensino Philosophico Paulistano", corporação de estudos de filosofia, á semelhança do "Ensaio Philosophico", da Côrte, perante o qual fôra Frei Francisco de Montalverne acclamado "o mais genuino representante da filosofia no Brasil". Do Ensaio Philosophico Paulistano era orgão a Revista Mensal do Ensino Philosophico Paulistano, na qual escreveram Ferreira Vianna, Benevides, Paulino de Souza, Antonio Carlos, Felix Xavier da Cunha, Sebastião Pereira, e, pelo tempo adeante, nomes que depois foram grandes nas letras e na politica - Theophilo Ottoni, Francisco Rangel Pestana, Francisco Quirino dos Santos, Antonio Joaquim de Macedo Soares, Affonso Celso, o Velho, Pedro Luiz, José Vieira Couto de Magalhães, Gaspar da Silveira Martins, Lafayette Rodrigues Pereira, e muitos outros.

Constituiu, sem contestação, antes do Onze de Agosto, a mais prestigiosa das sociedades academicas; e a Revista. Mensal, de que a nossa Biblioteca possue muito numeros, ainda hoje se relê com interesse.

Não se deve confundir essa Revista Mensal com os Ensaios Literarios, onde Bernardo Guimarães e Antonio Joaquim Ribas, o futuro Conselheiro Ribas, terçaram as primeiras armas, e cujo numero inicial se publicou em fins de 1847 ou em 1848.

Installou-se o "Ensaio Philosophico Paulistano" a 9 de Maio de 1850, e solemnisou-o o nosso Alvares de Azevedo, cuja prosa tersa, florida e erudita, ainda hoje atrae e empolga, não obstante certo requinte de pompas retoricas. Contava então 19 annos, e isso the escusa os defeitos, ao mesmo tempo que nos surprehende. Um anno antes, em 11 de Agosto de 1849, apenas com dezoito annos, foi-lhe incumbida a tarefa de celebrar o anniversario da fundação 
da Academia. Esta investidura, em meio aos talentos que o cercavam, mostra bem o prestigio com que os collegas o distinguiam.

Taes as horas de esplendor e de festa, de poesia e de mocidade. Outras vezes, porém, se fechava em casa. Não vinham amigos. Na escuridão da noite tremeluziam lampeões. Então o tedio, fantasma colossal, envolvia tudo, e o poeta recahia, de repente, nas tôrvas calmarias da inspiração, e sentia perto o halito frio da morte.

A lembrança de dois quinto-annistas, fallecidos, Feliciano Corrêa Duarte, que uma paixão desvairada levara ao suicidio, em 1850, e João Baptista da Silva Pereira, em 1851, pareciam-lhe presagiar a morte proxima. Por uma atração singular, é Alvares de Azevedo quem tece, á beira do tumulo, os panegiricos de um e de outro.

Parece-nos, ainda hoje, aos accentos da profunda emoção, que o orador academico se revê no destino escuro de um e outro collega.

Diz, por exemplo, referindo-se a Feliciano Duarte:

— "Porque morreu? Perguntai ás aves de arribação porque as leva de vencida o tufão da tempestade! ás estrellas, porque desmaiam e mergulham nas ondas! a Chatterton e Jacopo Ortiz, porque uma hora de febre esqueceu-os de uma existencia!

E a sua existencia se fadava brilhante! As glorias da tribuna, os triunfos do genio, e, talvez que outras palpitações mais ardentes - o amor: tudo isso era o seu futuro, azul e puro como os sonhos de vinte annos!

$\mathrm{E}$ tudo isso marchou ao sopro do nada! $\mathrm{E}$ o vento da morte, ao correr pela selva sagrada, mirrou o cedro mais soberbo".

Transparece, aqui, entre os gemidos da sua alma, a antevisão do proprio destino.

$\mathrm{E}$ é por isso que, á beira do tumulo do estudante Silva Pereira, lhe brotam dos labios estes conceitos:

"Navegantes miserrimos pelo oceano da morte, a nau, que conduz as nossas esperanças para o Oriente do futuro, 
tem uma sina terrivel! Cada anno uma victima se perde nas ondas, e a sorte escolhe, sorrindo, os melhores dentre nós. Ha um anno que aqui viemos, os mesmos de hoje, acompanhar um cadaver, e murmurar um adeus á mais bella das esperanças academicas. Parece que uma sina mysteriosa nos trouxe hoje para as reminiscencias amargas de uma noite fatal! E' mais uma das flôres da corôa da mocidade, que se desfolha ao vento do sepulcro! Ainda uma fronte que se dourava ao sol do futuro, como o alto das serranias ao fogo do sepulcro! é uma aurora sem dia, que se perdeu na noite de uma tempestade de inverno".

Perpassam os dramas intimos nestas linhas, como na carta que, em 1 de Março de 1850, escreveu do Rio a seu amigo e confidente Luiz Antonio da Silva Nunes.

Reproduziremos apenas este trecho:

"Não tenho passado ocioso estas ferias, antes bem trabalhadas de leitura tenho-as levado. Nesse pouco espaço de tres mezes escrevi um romance de duzentas e tantas paginas; dois poemas, um em cinco, e outro em dois cantos; uma analyse de Jacques Rolla, de Musset; e uns estudos literarios sobre a marcha simultanea da civilisação e poesia em Portugal, bastante volumosos; um de poema, em linguagem muito antiga, mais difficil de entender que as Sextilhas de Frei Antão, noutro gosto, porém, mais ao geito do $T h$. Rowley, de Chatterton.

A essa minha agitação de espirito sobrevem-me, ás vezes, um marasmo invencivel, horas daquellas que os navegantes temem, em que a calmaria descae no mar morto, e as velas caem ao longo dos mastros. Fallei-te sempre com a mão no coração; si algum dia eu morresse moço ainda, na minha febre de ambiciosas esperanças, si, -- pobre imaginação de poeta! — o gelo da morte me corresse na trama do cerebro, ha em algumas das minhas cartas a ti uma historia inteira de dois annos, uma lenda, dolorosa, sim, mas verdadeira, no seu pungir de ferro, como uma autopsia de soffrimentos. Luiz, é uma sina minha que eu amasse muito, e que ninguem me amasse. -- Eis a ironia que ahi me vem, 
no meu acabrunhar sombrio, nesse meu não crer do que os outros creem. Chamam-me frio; julgam que o egoismo e o orgulho m'o gelara inteiro. o nectar que se chama - a alma, daquella amphora maldicta que se chama - a vida!"

Basta de transcrever. $O$ que aqui fica é uma pagina ardente e dolorosa, em que toda a sua psychologia se retrata.

E o fatal prenuncio se realisa. A 10 de Março de 1853. no Rio, se lhe agravaram os sofrimentos, decorrentes de rapida doença, e, a 25 de Abril, sentindo que a morte se approximava, pediu á mãe que por um pouco se retirasse, levantou-se a meio da cama, amparado ao peito do irmão, tomou a mão paterna, beijou-a com os labios febris, e, voltando os olhos para o pae, expirou com estas palavras:

\section{Que fatalidade, meu pae!}

A 23 de Maio seguinte esta Academia se vestiu de lucto para render-lhe uma derradeira homenagem. Celebrou-a o Ensaio Philosophico Paulistano, de que era socio benemerito e fundador, sob a presidencia de Amaral Gurgel. Foi orador official Ferreira Vianna, a que se seguiram Felix Xavier da Cunha, Antonio Carlos, Duarte de Azevedo, Paulino de Souza, Sá e Benevides, e outros.

$\mathrm{E}$ assim passou sobre a terra esta juvenil figura de poeta e de academico, cuja fama vae crescendo com os tempos, e cuja personalidade, já lendaria, enche os nossos fastos na singela, mas expressiva commemoração desta noite.

Ella significa que, dentro e fóra desta Academia, não morreu a poesia na alma brasileira, na alma paulista. Através das noites frias e nevoentas, em meio ao estridor das officinas e das industrias, vive e vibra, immortal e sempre renascente, o idealismo creador que não morre, e que nos faz aspirar a um Brasil mais alto e mais nobre, unificado pelos genios que interpretaram a alma collectiva, e pelos estadistas que moldaram as vigas mestras do edificio nacional. 
Esse idealismo nos ha de redimir e illuminar na hora grave que atravessamos. Tenhamos confiança no futuro, e possam as saudades, que desfolhamos sobre o tumulo de Alvares de Azevedo, reflorir em esperanças de melhores dias.

\section{SPENCER VAMPRE'}

